\title{
Toxicity of Millettia ferruginea (Hochst) Baker against the Larvae and Adult Ticks of Boophilus decoloratus a One-Host Tick in Cattle
}

\author{
Manash Kumar Choudhury* and Yoseph Shiferaw \\ Department of Chemistry, Dilla University, Dilla, P.O Box 419, Ethiopia
}

\begin{abstract}
The present article reports the in vitro toxicity of the seed of Millettia ferruginea (Berbera) for the first time against the larvae and mature ticks of Boophilus decoloratus. The $20 \%, 40 \%, 60 \%, 80 \%$ and $100 \%$ concentrations of the seed oil were found to kill all ( $100 \%$ mortality) larvae after $16 \mathrm{hr}, 12 \mathrm{hr}, 8 \mathrm{hr}, 6 \mathrm{hr}$ and $2 \mathrm{hr}$ respectively. The $100 \%$ concentration of the petroleum extract (oil) of the seed caused $100 \%$ mortality of adult male, adult female and fully engorged female tick after $5 \mathrm{hr}, 7 \mathrm{hr}$ and $12 \mathrm{hr}$ respectively. The root and root bark showed less toxicity while leaves did not show any activity. Among petroleum ether, acetone and methanol, the acetone extract showed highest acaricidal activity.
\end{abstract}

Keywords: Acaricide, Boophilus decoloratus, Cattle, Fabaceae, In vitro, Millettia ferruginea, Tick

\section{Introduction}

The objective was to find an easy way for natural remedy utilizing a cheap natural resource. The present article gives an efficient solution to control the severe infestation caused by ticks. The infestation of cattle by tick, Boophilus decoloratus is highly prevalent (wide spread) in Ethiopia and all African countries including South Africa and Australia that leads to low production of milk, meat and inferior quality of skin. The low quality of skin becomes useless in leather industry and causes a serious economic loss in any country.

The aim was to utilize a particular natural source, Millettia ferruginea to solve this acute problem and make a trial experiment with the seed oil. Fortunately the first attempt was successful. The tree is readily available in the country and is a cheap source of getting medicine that occurs in nature.

The plant Millettia ferruginea (family: Fabaceae) is a large tree that grow up to 25 meter (approximately 75 feet) high. It is widely distributed all over Ethiopia within the agro climatic zones of 1000-2500 meter (approx 3,0007,500 feet) above the sea level. It is endemic to Ethiopia and is commonly known as 'Berbera' (in Amharic), Sotallo, Kotalu, Sari, Yego (in Afan Oromo), Hengedi-cho (in Sidama), Zaghia (in Wolaita), Dhadhato (in Gedeofa) languages ${ }^{1}$. The mature seeds in the powder form are used for catching fish due to its toxicity is a common practice in the country. The powder is spread over the water surface for stunning fish ${ }^{2}$. It is planted along the road sides and in agro forestry for decorative and agricultural purposes. Moreover, it serves as shade tree for coffee (Coffea arabica) farms and erosion control in Eastern and Southern parts of Ethiopia ${ }^{3-5}$. The tree is used for firewood, local construction of houses, tool handles, household tools, improving soil fertility (nitrogen fixing leguminous tree). The plant is traditionally used to treat skin infection ${ }^{6}$ and for dressing 'mujele' an infection caused by an insect present in the soil ${ }^{7}$. The seed extract of this plant has been observed to

*Author for correspondence

Email: mkchoudhury2001@yahoo.co.in 
be effective in controlling storage insect pests as adzuki bean beetle, Callasobruchus chinensis ${ }^{8}$, maize weevil, Sitophilus zeamais ${ }^{9}$. The seed powder of Berbera caused $100 \%$ mortality of the bean weevil, Zebrotes subfasciatus Boheman $^{10}$. Recent study showed that the aqueous crude seed extract was extremely effective in reducing the larval population of maize stalk borer Busseola fusca (fuller) (Lepidoptera: Noctuidae) ${ }^{11}$. A laboratory study showed that water extract of Berbera seed powder at different concentration levels $(10-40 \% \mathrm{w} / \mathrm{v})$ caused 93-100\% mortality against the different castes of adult Macrotermes termites ${ }^{12}$.

Various parasitic diseases are transmitted by different types of ticks present in the environment that stick to the bodies of different animals like cattle, sheep, goat, horse, donkey, dog, rabbit etc. The cattle and sheep are mostly affected due to large infestation of different types of ticks. Ethiopia suffers a serious economic loss and it has become a burning problem of the day in many African and Asian countries including Australia. The ticks not only suck blood from the cattle, sheep and other animals but also transmit various kinds of diseases to the animals. The cattle become anaemic and ill-health due to loss of blood resulting a low production of milk and meat, the skin becomes useless in leather industry due to the presence of a large number of holes in it caused by tick-bite. The cattle undergo premature death after a long period of suffering. Furthermore, the diseases are also likely to be transmitted to human being through uncooked milk and meat causing a serious health hazard in the society.

Boophilus decoloratus, the blue tick (family: Ixodidae or hard tick) is a one-host tick occurs throughout the Ethiopian region, Southern Asia especially in humid areas. It is parasitic chiefly on cattle and equines, but also found on sheep and goats, wild ungulates and dogs. The engorged females have a slate-blue colour and pale yellow legs. It transmits the disease Babesia bigemina known as Babesiosis (rise in temperature to high fever, in appetence (loss of appetite), red urine, anaemia, jaundice, emaciation, death ${ }^{13}$. A female lays around 2500 eggs $^{14}$.

The toxicity of Neem seed oil against the larvae of Amblyomma variegatum, a three-host tick in cattle $^{15}$, toxicity of Neem seed oil against the larvae of Rhipicephalus sanguineus, a three-host tick in $\operatorname{dog} 16$, toxicity of Neem leaf against the larvae of Boophilus decoloratus, a one-host tick in cattle ${ }^{17}$, toxicity of Neem seed oil against the larvae of Boophilus decoloratus, a one-host tick in cattle ${ }^{18}$ toxicity of Khaya senegalensis (Meliaceae) seed oil against the larvae of Boophilus decoloratus, a one-host tick in cattle were published earlier ${ }^{19}$.

The isolation of rotenone, deguelin and tephrosin ${ }^{20}$, durmillone and ferrugone ${ }^{21}$ from Berbera seeds, barbigerone from the seeds of Tephrosia barbigera ${ }^{22}$ were previously published. Many isoflavones namely ferrugone, durmillone from the seeds, jamaicin, ichthynone, 7-hydroxy-5,6-dimethoxy-3',4'-methylenedioxy isoflavone, flemichapparin-B from the bark, durmillone, 5-methoxy-durmillone, 5-hydroxy durmillone, calopogonium isoflavone-A, 4-hydroxy-loncocarpine, calopogonium isoflavone- $\mathrm{B}$, barbigerone, preferrugone, predurmillone, prebarbigerone, pre-5-methoxy durmillone were earlier reported from this plant ${ }^{23-25}$.

The present article reports the acaricidal activity of Millettia ferruginea seed against Boophilus decoloratus for the first time. It describes the in vitro toxicity of the crude petroleum ether extract (oil), acetone extract (oil) and methanol extract (oil) of the seed, leaf, root and root bark of this plant against the larvae and mature male and female ticks. The toxicity of the crude extract of the seed of this plant against the larvae of Amblyomma variegatum, a three-host tick in cattle was published earlier by $\mathrm{us}^{26}$.

\section{Material and Methods}

\subsection{Apparatus and Chemicals}

Soxhlet apparatus was used for extraction. All the solvents were obtained from Fluka Chemie, Sigma Aldrich, Germany and distilled before use. Petroleum ether used had b.p. $60-80{ }^{\circ} \mathrm{C}$.

\subsection{Collection of Plant Material}

The different parts of the plant such as seeds, leaves, root barks and roots were collected from a place close to Dilla University, Dilla, Ethiopia. The freshly collected plant materials were washed with water and dried under shade at room temperature. The dried samples (root bark and root) were reduced to small pieces, ground to a coarse powder using metal coffee grinder. The seeds were powdered using a grinder machine. 


\subsection{Extraction in Soxhlet}

The powdered seed $(5 \mathrm{~g})$ was extracted with petroleum ether (bp.60-80 ${ }^{\circ} \mathrm{C}$ ) in a $100 \mathrm{ml}$ round bottom flask for 6 hours at the rate of 6 cycles/hour. Viscous yellow coloured oil (1.87 g, yield 37.5\%) was obtained after complete removal of the solvent in a rotavapor. The analysis of one-way ANOVA indicated that statistically no significant variation $(\mathrm{p}<0.05)$ was observed in the yield in the extraction after 6 hours. Similarly, the powder leaf (5g), powder root $(5 \mathrm{~g})$ and powder root bark $(5 \mathrm{~g})$ were separately extracted with petroleum ether (b.p. $60-80^{\circ} \mathrm{C}$ ) and viscous oil was obtained in each case after evaporation of solvent. Again powder seed (5g) was extracted with acetone and powder seed (5g) extracted with methanol separately.

\subsection{Collection of Ticks}

The larvae of one-host tick, Boophilus decoloratus, adult male and female ticks were used in this study. The engorged female (full of blood), mature male and female ticks were collected from the bodies of cattle in Oromiya regional state, Borana zone, Abaya woreda, Samaro kebele near Dilla town, Ethiopia. The engorged female tick was detached from the body of the cattle by hand picking, put in a clean test tube plugged with cotton and incubated at $30^{\circ} \mathrm{C}$ with a relative humidity of $80-100 \%$. After the complete laying of eggs the tick died and the dead female tick was discarded. The eggs laid in the tube were transferred into a clean tube with a cotton plug. The eggs were kept under the same incubating conditions until they hatched into larvae and then starved in the incubator at $30^{\circ} \mathrm{C}$ for one week before use. The adult ticks were collected in a similar way from the bodies of cattle and kept in a clean glass tubes plugged with cotton and the bioassay carried out soon after 30 minutes of collection. All the ticks were properly identified at Holeta Research Centre, Ministry of Agriculture and Rural Development, National Animal Health Diagnostic and Investigation Centre, Addis Ababa, Ethiopia.

\subsection{Bioassay Analysis}

The solvent was completely removed from the oil in rotary evaporator before the experiment. Petri dishes ( $9 \mathrm{~cm}$ diameter) with one sheet of filter paper inside of the same size were used. Five different volumes of seed oil were dissolved in $1 \mathrm{ml} \mathrm{CHCl}$ separately to prepare solutions of different concentrations, i.e., $1 \mathrm{ml}$ (dissolved in $1 \mathrm{ml} \mathrm{CHCl}, 100 \%$ ), $0.8 \mathrm{ml}$ (dissolved in $1 \mathrm{ml} \mathrm{CHCl}_{3}$, $80 \%$ ), $0.6 \mathrm{ml}$ (dissolved in $1 \mathrm{ml} \mathrm{CHCl}_{3}, 60 \%$ ), $0.4 \mathrm{ml}$ (dissolved in $1 \mathrm{ml} \mathrm{CHCl}_{3}, 40 \%$ ), $0.2 \mathrm{ml}$ (in $1 \mathrm{ml} \mathrm{CHCl}_{3}$, $20 \%)$ and $1 \mathrm{ml}$ distilled water ( $0 \%$, control) were evenly soaked (spread with a spatula) in different filter papers of each Petri dish and $\mathrm{CHCl}_{3}$ was completely removed by exposing the plates at room temperature and blowing with cold air. Fifteen (15) larvae were put inside in each plate with the help of a soft brush and then monitored at certain interval of time. The number of larvae found dead in each plate was recorded. The experiment was repeated four times.

\section{Results and Discussion}

Experiment showed that the toxic constituent(s) is/are totally absent in the leaf. The toxicity was found highest in the seed followed by the root and root bark. $100 \%$ mortality was observed after 2 hours with seed oil, $2 \frac{1}{2}$ hours with root oil and 3 hours with root bark oil. The results are summarized in Table 1.

$100 \%$ mortality of the adult male, adult female and fully engorged female was observed after 5, 7 and 12 hours respectively when tested with the seed oil obtained from petroleum ether extract. This result indicated that the acaricidal activity of the extract of the seed depends on sex and stage of the tick species. The adult females and engorged females took longer time to die than the adult males; the engorged one took longest time. The female ticks showed higher resistance towards the chemical(s) present in the seed. The results are summarized in Table 2.

Further experiment showed that the mortality of larvae was concentration and time dependent. 100\% mortality was observed with $20 \%, 40 \%, 60 \%, 80 \%$ and $100 \%$ seed oil after 16 hours, 12 hours, 8 hours, 6 hours and 2 hours respectively. One way ANOVA analysis applied to the data showed statistically significant difference in mortality at the probability level of $\mathrm{p}<0.05$. With $0 \%$ concentration (water, control) there was no mortality at any time. The results are summarized in Table 3.

Variable toxicities were observed when different extracts obtained from petroleum ether, acetone and methanol tested against the larvae. Extract (oil) obtained from acetone showed highest toxicity. There was 100\% 
Toxicity of Millettia ferruginea (Hochst) Baker against the Larvae and Adult Ticks of Boophilus decoloratus a One-Host Tick in Cattle

Table 1: Toxicity of petroleum ether extract (oil) of leaf, seed, root and root bark against the larvae of Boophilus decoloratus

\begin{tabular}{|c|c|c|c|c|}
\hline \multirow[t]{2}{*}{ Plant material } & \multicolumn{4}{|c|}{$\begin{array}{l}\text { Total number of larvae died after } 1 / 2 \text { hour } \\
\text { interval of time with } \% \text { mortality }\end{array}$} \\
\hline & $11 / 2 \mathrm{hr}$ & $2 \mathrm{hr}$ & $2 \frac{1}{2} \mathrm{hr}$ & $3 \mathrm{hr}$ \\
\hline \multirow[t]{2}{*}{ Leaf (1ml) } & 0 & 0 & 0 & 0 \\
\hline & $0 \%$ & $0 \%$ & $0 \%$ & $0 \%$ \\
\hline \multirow[t]{2}{*}{ Seed (1 ml) } & 14.8 & 15 & & \\
\hline & $99 \%$ & $100 \%$ & & \\
\hline \multirow[t]{2}{*}{ Root (1 ml) } & 11.8 & 14.8 & 15 & \\
\hline & $79 \%$ & $99 \%$ & $100 \%$ & \\
\hline \multirow[t]{2}{*}{ Root bark (1ml) } & 11.0 & 13.3 & 14.8 & 15 \\
\hline & $73 \%$ & $89 \%$ & $99 \%$ & $100 \%$ \\
\hline \multirow[t]{2}{*}{ Water (control, 0\%) } & 0 & 0 & 0 & 0 \\
\hline & $0 \%$ & $0 \%$ & $0 \%$ & $0 \%$ \\
\hline
\end{tabular}

15 larvae were used in each plate, the values are given as mean of 4 replicates

Table 2: Toxicity of the petroleum ether extract (oil) of the seed against adult male, adult female and fully engorged female of Boophilus decoloratus

\begin{tabular}{lccc}
\hline $\begin{array}{l}\text { Volume of PE } \\
\text { extract used }\end{array}$ & Nature of tick & $\begin{array}{c}\text { Number of } \\
\text { ticks used }\end{array}$ & $\begin{array}{c}100 \% \text { mortality } \\
\text { of ticks after }\end{array}$ \\
\hline $1 \mathrm{ml}$ & Adult male & 20 & 5 hours \\
$1 \mathrm{ml}$ & Adult female & 20 & 7 hours \\
$1 \mathrm{ml}$ & $\begin{array}{c}\text { Fully engorged } \\
\text { female }\end{array}$ & 20 & 12 hours \\
\hline
\end{tabular}

The values are given as mean of 4 replicates

Table 3: Toxicity of petroleum ether extract (oil) against larvae of Boophilus decoloratus at different concentrations and different interval of time

\begin{tabular}{|c|c|c|c|c|c|c|c|c|c|}
\hline \multirow[t]{2}{*}{ Plate No } & \multirow{2}{*}{$\begin{array}{c}\text { Volume of } \\
\text { extract soaked }\end{array}$} & \multicolumn{8}{|c|}{ Number of dead larvae during interval of 2 hrs with \% mortality } \\
\hline & & $0-2 \mathrm{hr}$ & $2-4 \mathrm{hr}$ & 4-6 hr & $6-8 \mathrm{hr}$ & $8-10 \mathrm{hr}$ & $10-12 \mathrm{hr}$ & $12-14 \mathrm{hr}$ & $14-13 \mathrm{hr}$ \\
\hline \multirow[t]{2}{*}{1} & $0.2 \mathrm{ml}(20 \%)$ & 0.5 & 1.5 & 2.3 & 2.2 & 3 & 3 & 1.5 & 1 \\
\hline & & $3 \%$ & $13 \%$ & $29 \%$ & $43 \%$ & $63 \%$ & $83 \%$ & $93 \%$ & $100 \%$ \\
\hline \multirow[t]{2}{*}{2} & $0.4 \mathrm{ml}(40 \%)$ & 1 & 2.5 & 3 & 3.5 & 2 & 3 & & \\
\hline & & $7 \%$ & $23 \%$ & $43 \%$ & $67 \%$ & $80 \%$ & $100 \%$ & & \\
\hline \multirow[t]{2}{*}{3} & $0.6 \mathrm{ml}(60 \%)$ & 5 & 4 & 1.5 & 4.5 & & & & \\
\hline & & $33 \%$ & $60 \%$ & $70 \%$ & $100 \%$ & & & & \\
\hline \multirow[t]{2}{*}{4} & $0.8 \mathrm{ml}(80 \%)$ & 8.0 & 4 & 3 & & & & & \\
\hline & & $53 \%$ & $80 \%$ & $100 \%$ & & & & & \\
\hline \multirow[t]{2}{*}{5} & $1.0 \mathrm{ml}(100 \%)$ & 15 & & & & & & & \\
\hline & & $100 \%$ & & & & & & & \\
\hline \multirow[t]{2}{*}{6} & $\mathrm{H}_{2} \mathrm{O}$ & 0 & 0 & 0 & 0 & 0 & 0 & 0 & 0 \\
\hline & $1 \mathrm{ml}(0 \%)$ & $0 \%$ & $0 \%$ & $0 \%$ & $0 \%$ & $0 \%$ & $0 \%$ & $0 \%$ & $0 \%$ \\
\hline
\end{tabular}

15 larvae were used in each plate, the values are given as mean of 4 replicates 
mortality after 1/1/2 hour, 2 hours and 5 hours with acetone, petroleum ether and methanol extract respectively. The results are summarized in Table 4. Statistical analysis of the results obtained in Table 3 is shown in Table 5.

The acetone extract of the seed showed the highest efficacy than that of petroleum ether and methanol extracts. The comparative studies of the present findings revealed that the petroleum ether extract of the seed (oil) possesses much higher acaricidal activity against Amblyomma variegatum ${ }^{25}$. $100 \%$ concentration of the seed oil took 1.5 hours for $100 \%$ mortality for $A$. variegatum and 2 hours for $B$. decoloratus. In other words Amblyomma variegatum is more sensitive than Boophilus decoloratus towards the toxicity of seed oil of this plant. The seed oil was found to be safe to the skin of the cattle. When the oil (100\% concentration) was applied to the body (skin) of the cattle and kept under close observation for more than a week, no irritation or inflammation on the skin of the cattle was observed. No larvae or adult male/female were found within the close vicinity of the oil applied. This showed the toxic nature of the oil towards the tick.

Financial constrained smallholding farmers cannot afford to buy insecticide and application equipment. For these reasons attention is being given to the use of ecologically safe and cheaper methods such as botanicals against various pests and insects. The isolation of crude oil from seed is inexpensive and has been made simple that can be easily adopted by farmers for the management of ticks. We discovered that petroleum ether is easily replaced by water, the cheapest solvent for isolation of the oil. The powder seed is heated with water and on cooling at room temperature, oil floats on the surface. This oil is easily separated by decantation and directly applied on the body of a cattle and get rid of ticks very quickly. This method is very simple, fast and efficient; it does not need any organic solvent or chemical. Here lies the beauty of the work. The oil isolated by this procedure and oil extracted with petroleum ether or acetone showed identical $R_{f}$ values on TLC indicating the active compound(s) present did not undergo any chemical change on heating and they are thermally stable compounds. The water and petroleum extracts both exhibited same toxicity results in laboratory experiment. Since the seed oil of Millettia ferruginea is inexpensive, readily available and bio-degradable, the seed of this plant undoubtedly will be a better substitute for any synthetic insecticides which are expensive, not bio-degradable and suffer from serious side effects. The isolation, characterization and bioassay experiments with isolated compounds are in progress.

Table 4: Acaricidal activity of different extracts against larvae at different interval of time with \% mortality

\begin{tabular}{|c|c|c|c|c|c|c|c|c|c|c|}
\hline \multirow[t]{2}{*}{ Extract } & \multicolumn{10}{|c|}{ Total number of larvae died and \% Mortality at different interval of time } \\
\hline & $1 / 2 \mathrm{hr}$ & $1 \mathrm{hr}$ & $1 \frac{1}{2} \mathrm{hr}$ & $2 \mathrm{hr}$ & $2 \frac{1}{2} \mathrm{hr}$ & $3 \mathrm{hr}$ & $3 \frac{1}{2} \mathrm{hr}$ & $4 \mathrm{hr}$ & $4 \frac{1}{2} \mathrm{hr}$ & $5 \mathrm{hr}$ \\
\hline \multirow[t]{2}{*}{$\mathrm{PE}(1 \mathrm{ml})$} & 6.00 & 10.65 & 14.55 & 15 & & & & & & \\
\hline & $40 \%$ & $71 \%$ & $97 \%$ & $100 \%$ & & & & & & \\
\hline \multirow{2}{*}{$\begin{array}{l}\text { Acetone } \\
(1 \mathrm{ml})\end{array}$} & 6.45 & 11.70 & 15 & & & & & & & \\
\hline & $43 \%$ & $78 \%$ & $100 \%$ & & & & & & & \\
\hline \multirow[t]{2}{*}{$\mathrm{CH}_{3} \mathrm{OH}(1 \mathrm{ml})$} & --- & 2.25 & 3.45 & 6.00 & 7.50 & 8.70 & 11.25 & 11.55 & 13.50 & 15 \\
\hline & & $15 \%$ & $23 \%$ & $40 \%$ & $50 \%$ & $58 \%$ & $75 \%$ & $77 \%$ & $90 \%$ & $100 \%$ \\
\hline
\end{tabular}

15 larvae were used in each plate; the values are given as mean of 4 replicates

Table 5: Statistical analysis of the results obtained in Table 3. Results of ANOVA tests justifying the effect of time interval on the mortality of larvae of Boophilus decoloratus exposed to different concentrations of petroleum ether extract.

\begin{tabular}{lcccccc}
\hline $\begin{array}{l}\text { Source of } \\
\text { variation }\end{array}$ & SS & DF & MS & F & F-critical & P-values \\
\hline Between groups & 115.091 & 7 & 16.44157143 & 2.668490626 & 2.312741187 & 0.027070235 \\
Within groups & 197.164 & 32 & 6.161375 & & & \\
Total & 312.255 & 39 & & & & \\
\hline
\end{tabular}

SS: sum square, DF: degree of freedom, MS: mean square, F: F statistics 
The seed oil on further purification over column chromatography afforded a colourless oil and few isoflavonoid compounds. These isoflavones are expected to be bioactive compounds and the evaluation of bioactivity is in progress. After preliminary investigation the colourless oil was characterized as a high molecular weight triglyceride with saturated and unsaturated fatty acids in the ester linkage by spectral analysis. The complete structure elucidation is in progress. The oil obtained (37.5\% yield) from the seed has a potential application for biodiesel, soap and glycerol (glycerine) production. At present the whole world is looking for bio-diesel since the petrol and diesel are very expensive. The present trend in the world is to explore natural resources for curing diseases of human being, plant kingdom and live stock animals. Scientists are nowadays encouraging and appreciating this type of simple and low cost involved work which has an immediate application in the society.

The results of ANOVA single factor test at $\mathrm{P}=0.05$ level of significance using Microsoft Excel are shown in Table 5. The F-value is found to be 2.668490626 for 'time interval' and the value is greater than its F-critical value 2.312741187. The 'time interval' factor is significant at $\mathrm{P}=0.05$ level. The $\mathrm{P}$ value of $0.027070235(\mathrm{P}<0.05)$ indicates that the 'time interval' factor is statistically highly significant (95\%) on the mortality of larvae exposed to different concentrations.

\section{Acknowledgement}

The authors are thankful to Mr. Asish Das, Department of Electrical Engineering, National Institute of Technical Teachers' Training and Research, Block-FC, Sector-III, Salt Lake City, Kolkata-700 106, India for his technical assistance in statistical analysis during preparation of the manuscript.

\section{References}

1. Bekele A. Useful trees and shrubs for Ethiopia: Identification, propagation and Management for 17 agro climatic zones, Nairobi: RELMA in ICRAF project, Nairobi, Kenya. 2007.

2. Karunamoorthi K, Bishaw D, Mulet T. Toxic effects of traditional Ethiopian fish poisoning plant Millettia ferruginea (Hochst) seed extract on aquatic macro invertebrates. European Review for Medical and Pharmacological Sciences. 2009; 13:179-85.

3. Teketay D, Tegineh A. Shade trees of coffee in Harare, Eastern Ethiopia. The International Tree Crops Journal. 1991; 7:17-27.

4. Tadesse H, Legesse N, Olsson M. Mellittia ferruginea from Southern Ethiopia: impacts on soil fertility and growth of maize. Agroforestry Systems. 2000; 48:9-24.

5. Azene B. Useful trees and shrubs of Ethiopia; identification, propagation and management for 17 agroclimatic zones. In Technical Manual No.6. RELMA in ICRAF Project Kenya. 2007. p. 550. ISBN: 978-92905-92129.

6. Mesfin F, Demissew S, Telehaymanot T. An ethno botanical study of medicinal plants of Wonago, Woreda, SNNPR, Ethiopia. J Ethno Biol and Ethno Med. 2009; 5(28):1-8.

7. Teklelehaymanot T, Giday M. Ethno Botanical study of medicinal plants used by people in Zeige Peninsula, North-western Ethiopia. J Ethno Biol Ethno Med. 2007; 3(12):1-12.

8. Damte T, Chichaybelu M. The efficacy of some botanicals in controlling Adzuki bean beetle, Callosobruchus chinensis in stored chickpea. Tropical Sci. 2002; 42:192-5.

9. Jembere B. Evaluation of the toxicity potential Millettia ferruginea (Hochest) Baker against Sitophilus zeamais Mots. International J Pest Management. 2002; 42(1):2932.

10. Jembere B, Namukobe J, Benard TK, Dagne E. Extracts of Millettia ferruginea, Tephrosia vogellii and Tephrosia pentaphylla against the bean weevil Zabrotes subfasciatus (Boheman). Sinet: Ethiopian J Sci. 2007; 30:49-54.

11. Tilahun B, Azerefegne F. Efficacy of the aqueous crude seed extract of Millettia ferruginea (Fabaceae) on the maize stemborer Busseola fusca (Lepidoptera: Noctuidae) in the field. International J Tropical Insect Sci. 2013; 33(4):256-63.

12. Getahun D, Jembere B. Evaluation of toxicity of crude extracts of some botanicals on different castes of Macrotermes termites. Paste Management Journal of Ethiopia. 2006; 10:15-23.

13. Shaw RD, Thorburn JA, Wallace HG. Cattle Tick Control, Prepared by Members of The Wellcome Research Organisation: Cooper Division Wellcome Foundation Ltd, London, England. 1970. p. 15.

14. Soulsby EJL. Helminths, Arthropods and Protozoa of Domesticated Animals, 7th edition, English Language Book Society (ELBS)/Bailliere Tindall, London, England. 1982. p. 468.

15. Ndumu AA, George JBD, Choudhury MK. Toxicity of neem seed oil (Azadirachta indica) against the larvae 
of Amblyomma variegatum a three-host tick in cattle. Phytotherapy Research. 1999; 13:532-4.

16. Choudhury MK. Toxicity of neem seed oil (Azadirachta indica) against the larvae of Rhipicephalus sanguineus a three-host tick in dog. J Parasitic Diseases. 2001; 25(11): 46-7.

17. Choudhury MK. Efficacy of neem leaf (Azadirachta indica, family: Meliaceae) in the Control of larvae of Boophilus decoloratus, a one-host tick in cattle. J Nepal Pharm Assocn. 2003; 21(1):41-3.

18. Choudhury MK. Toxicity of neem seed oil against the larvae of Boophilus decoloratus, a one-host tick in cattle. Indian J Pharm Sci. 2009 Sep-Oct; 562-3.

19. Choudhury MK, Boshe FD. Toxicity of Khaya senegalensis seed oil against the larvae of Boophilus decoloratus: a onehost tick in cattle. Proceedings of Zoological Soc. 2013; 66(2): 137-40. Published online 17 Jan. DOI: 10.1007/ s12595-012-0058-8.

20. Clark EP. The occurrence of rotenone and related substances in the seeds of the Berebera tree. A procedure for the separation of deguelin and tephrosin. J Am Chem Soc. 1943 ; 65:27-9.

21. Highet RJ, Highet PF. The structure of two isoflavones from the Abyssinian Berebera tree. J Org Chem. 1967; 32:1055-8.

22. Vilain C. Barbigerone, a new pyranoisoflavone from seeds of Tephrosia barbigera. Phytochemistry. 1980; 19:988-9.

23. Dagne E, Bekele A, Waterman PG. The flavonoids of Millettia ferruginea subsp. Ferruginea and subsp. Darassana in Ethiopia. Phytochemistry. 1989; 28(7):1897-900.

24. Dagne E, Bekele A, Noguchi H, Shibuya M, Sankawa U. O-geranylated and O-prenylated flavonoids from Millettia ferruginea. Phytochemistry. 1990; 29(8):2671-73.

25. Dagne E, Bekele A. C-prenylated isoflavones from Millettia ferruginea. Phytochemistry. 1990; 29(8):2679-82.

26. Choudhury MK, Shiferaw Y, Hussen A. Toxicity of Millettia ferruginea darasana (family: Fabaceae) against the larvae and adult ticks of Amblyomma variegatum Fabricius, a three host tick in cattle. J. Parasitic Diseases. 2013; 39:298-302. DOI: 10.1007/s12639-013-0311-8. 